\section{Custo-efetividade da escovação dental supervisionada convencional e modificada na prevenção da cárie em molares permanentes de crianças de 5 anos de idade}

\author{
Cost-effectiveness of conventional and modified \\ supervised toothbrushing in preventing caries in \\ permanent molars among 5-year-old children
}

\author{
1 Faculdade de Saúde \\ Pública, Universidade de São \\ Paulo, São Paulo, Brasil. \\ Correspondência \\ P. Frazão \\ Faculdade de Saúde Pública, \\ Universidade de São Paulo. \\ Av. Dr. Arnaldo 715, \\ São Paulo, SP \\ 01246-904, Brasil. \\ pafrazao@usp.br
}

\section{Abstract}

The cost-effectiveness of a modified supervised toothbrushing program was compared to a conventional program. A total of 284 five-year-old children presenting at least one permanent molar with emerged/sound occlusal surface participated. In the control group, oral health education and dental plaque dying followed by toothbrushing with fluoride dentifrice was carried outfour times per year. With the test group, children also underwent professional cross-brushing on surfaces of first permanent molar rendered by a dental assistant five times per year. Enamel/ dentin caries were recorded on buccal, occlusal and lingual surfaces of permanent molars for a period of 18 months. The incidence density (ID) ratio was estimated using Poisson's regression model. The ID was 50\% lower among boys in the test group ( $p=0.016)$. The cost of the modified program was US\$1.79 per capita. The marginal cost-effectiveness ratio among boys was US\$ 6.30 per avoided carie. The modified supervised toothbrushing program was shown to be cost-effective in the case of boys.

Dental Caries; Toothbrushing; Molar; Primary Prevention; Program Evaluation

\section{Introdução}

Aqueles que planejam, oferecem, recebem ou pagam por serviços de saúde enfrentam questões práticas recorrentes na gestão desses serviços: quem deveria fazer certas atividades; quais atividades deveriam ser realizadas; para quem; como as atividades definidas deveriam ser realizadas; empregando quais recursos 1 .

A partir dos anos 90, em vários municípios brasileiros, foi desenvolvido o chamado programa de procedimentos coletivos. Esse programa consistia de um conjunto de atividades de caráter educativo e de proteção específica à saúde bucal, financiadas com recursos do Fundo Nacional de Saúde 2. Naqueles que não dispunham de água de abastecimento público fluoretada, a principal medida para enfrentar o problema da cárie dentária infantil foi esse programa que compreendia um conjunto de procedimentos composto por exame epidemiológico, educação em saúde, bochechos fluorados e higiene bucal supervisionada, desenvolvidos em grupos populacionais.

As normas operacionais do SUS, editadas nos últimos anos, mantiveram, com algumas modificações, os procedimentos coletivos. A última alteração foi aprovada na Portaria MS $n^{o}$. 95/2006. Conforme o Artigo 1o, os Procedimentos Coletivos (código 03.011.01-1) foram excluídos da Tabela de Procedimentos do Sistema de Informação Ambulatorial do Sistema Único de Saúde (SIA-SUS), sendo incluídas as atividades expli- 
citadas no Artigo 3ọ, entre as quais, Ação Coletiva de Escovação Dental Supervisionada (código 03.011.02-0), objeto da presente investigação ${ }^{3}$.

A exposição diária ao creme dental fluorado é uma medida preventiva com reconhecida força de evidência 4,5, e uma das razões apontadas para o declínio da cárie em escolares brasileiros são os programas de escovação supervisionada, nos quais o creme dental fluorado é empregado 6. Muitos auxiliares são envolvidos, e uma grande quantidade de recursos são gastos anualmente. Essa ação consiste de educação em saúde bucal e evidenciação de placa bacteriana seguida de escovação supervisionada com creme dental fluorado executada trimestralmente por auxiliares odontológicos 7 .

A atenção à saúde bucal tem sido postulada como uma das dimensões da atenção primária à saúde, e a cobertura da ação mencionada tem sido um indicador entre outros assumidos no pacto da atenção básica ${ }^{3}$. A maioria dos programas dirige os seus esforços para as primeiras séries do ensino fundamental, período em que ocorre o irrompimento dos primeiros dentes permanentes, entre os quais, o primeiro molar que concentra a maior carga do ataque de cárie 8 .

Entretanto, nenhuma avaliação econômica foi publicada sobre esse tipo de ação no contexto brasileiro. No plano internacional, são escassos os estudos. Numa busca na base de dados PubMed com as palavras escovação dental (toothbrushing) e custo (cost) em 14 de fevereiro de 2011; em todos os campos de indexação, foram identificados 82 artigos, dos quais, 14 eram estudos de revisão, e apenas dois correspondiam a estudos de avaliação econômica da escovação dental supervisionada 9,10 .

Estudos avaliativos de ações da atenção básica incluindo o custo-efetividade da escovação dental supervisionada em áreas abastecidas por água fluoretada são essenciais para subsidiar os gestores do SUS. Considerando as interdições de natureza ética para a constituição de um grupo de controle, o objetivo deste estudo foi avaliar o custo-efetividade de um programa modificado de escovação dental supervisionada na prevenção da cárie dentária em primeiros molares permanentes, em relação ao programa convencional.

\section{Métodos}

Um estudo controlado, randomizado e duplo cego, de intervenção comunitária para ser analisado em nível individual foi conduzido durante 18 meses numa coorte dinâmica de pré-escolares matriculados em seis unidades localizadas nu- ma área de baixa renda e com água fluoretada (0,7mgF/L), na cidade de São Vicente, Brasil.

O protocolo foi aprovado pelo Comitê de Ética em Pesquisa da Universidade Católica de Santos (no. 4843-20-2005). Pais/responsáveis dos participantes assinaram o termo de consentimento livre e esclarecido. O ensaio foi registrado na base eletrônica Current Controlled Trials (http://www. controlled-trials.com), sob o número ISRCTN (International Standard Randomised Controlled Trial Number) 18548869.

As pré-escolas foram distribuídas aleatoriamente em unidades de teste e de controle. Todas as crianças de cinco anos de idade apresentando, ao menos, um molar permanente com uma ou mais superfícies expostas e hígidas foram consideradas elegíveis.

Nas unidades de controle, o programa convencional composto por educação em saúde bucal e evidenciação de placa bacteriana seguida de escovação com creme dental fluorado (1.100 $\mu \mathrm{gF} / \mathrm{g})$ supervisionada por um auxiliar de saúde bucal foi realizado quatro vezes por ano. O componente educativo foi desenvolvido por meio de uma atividade lúdica, em sala de aula, com duração de 30 a 40 minutos, na qual os participantes eram estimulados a identificar os amigos e os inimigos da saúde dos dentes. Em seguida, por sala de aula, as crianças recebiam uma escova dental infantil e se dirigiam ao pátio coberto da escola onde havia uma pia com várias torneiras e um espelho de tamanho apropriado e fixado numa posição adequada à estatura das crianças. Nos demais dias letivos, escovação diária, supervisionada indiretamente pelos professores, foi realizada no pátio coberto da escola. Nas unidades de teste, além dessa atividade convencional, o auxiliar de saúde bucal foi capacitado para aplicar, nos molares permanentes em erupção, tanto superiores quanto inferiores, a técnica de escovação vestíbulo-lingual usando a escova do participante 11. Estudos de base clínica têm mostrado a eficácia da remoção da placa bacteriana nas superfícies de molares permanentes em erupção por meio dessa técnica 12,13,14. A frequência da atividade foi aumentada para cinco vezes ao ano por algumas razões. Aumentar a frequência de desorganização da placa poderia colaborar para o efeito final. Havia condições operacionais para incluir mais uma atividade no primeiro semestre letivo que compreendia 150 dias ou cinco meses em vez de 120 dias disponíveis regularmente no segundo semestre. O efeito do creme dental fluorado aumenta conforme a frequência do uso 5 . O auxiliar responsável pelo programa nas unidades de teste foi orientado a inclinar a cabeça da criança para trás a fim de obter, com iluminação natural, uma visualização apropriada do espaço 
retromolar e, assim, obter uma boa aplicação da técnica mesmo em molares inclinados. Durante o ensaio, amostras do creme dental empregado e da água de abastecimento da escola e de seu entorno foram examinadas em relação ao teor de fluoreto, segundo métodos padronizados pelo Laboratório de Bioquímica da Faculdade de Odontologia de Piracicaba da Universidade Estadual de Campinas.

Um dentista calibrado foi responsável por todos os exames. Antes do primeiro e do terceiro exame, a concordância intraexaminador e com um examinador padrão com experiência em levantamentos epidemiológicos (M.H.M.G.) foi verificada. A consistência intraexaminador e com examinador padrão foi avaliada por meio da estatística kappa. Os participantes e o examinador não foram informados sobre quais unidades eram de controle e quais eram de teste. O auxiliar responsável pelas atividades nas unidades de controle foi mantido sem conhecimento sobre as características do programa modificado realizado por outro auxiliar nas unidades de teste.

As crianças não escovavam seus dentes antes dos exames que foram realizados em um período distinto daquele empregado para a intervenção nas pré-escolas. Uma sonda de ponta esférica e um espelho bucal plano foram usados. Data de nascimento, sexo e cor da pele dos participantes foram registrados. Dados para o cálculo da experiência de cárie na dentição decídua, conforme os critérios recomendados pela Organização Mundial da Saúde, foram obtidos no exame linha de base 15 . Em todas as observações, a área posterior ao segundo molar decíduo foi examinada. O espaço foi classificado conforme o irrompimento do primeiro molar permanente. O dente foi considerado irrompido quando qualquer ponto da superfície de esmalte podia ser alcançado pela sonda. Espaço sem a presença de superfície de dente permanente foi registrado como dente não erupcionado. As superfícies dos molares permanentes foram categorizadas como sadias - nenhuma evidência de cavidade ou perda de tecido igual ou maior do que $0,5 \mathrm{~mm}$; cárie de esmalte - com, ao menos, 0,5mm de perda de tecido e nenhuma evidência que a cavitação atingiu a dentina 16; cárie de dentina - perda de tecido alcançando a dentina ou nítida presença de cavidade, esmalte socavado ou base/parede amolecida 15; e restaurada - presença de selante ou obturação temporária ou definitiva. A sonda foi usada para limpar a superfície dentária de placa e outros depósitos antes do exame e checar a textura da superfície de uma lesão sem penetrá-la. Níveis de flúor na água de beber e no creme dental foram controlados durante o estudo.
Embora a pré-escola tenha sido empregada como unidade de randomização a fim de evitar o efeito resultante do intercâmbio de conhecimentos e troca de experiências entre os sujeitos da pesquisa, o nível individual foi adotado como nível de inferência do desfecho sob o estudo. O tamanho da amostra foi estimado com base em um intervalo de 95\% de confiança (IC95\%) e poder estatístico de $80 \%$. Para avaliar uma razão maior ou igual a dois entre os dois grupos, considerando uma estimativa de 2,5\% (3 superfícies cariadas em cada 120 superfícies) no grupo de controle, eram necessárias 247 crianças com, ao menos, seis superfícies irrompidas sob risco ${ }^{17}$. A participação das crianças foi controlada. Aquelas que tiveram cinco ou mais faltas por mês na préescola foram excluídas da análise.

A fim de explorar diferenças nas características do grupo de teste e de controle no início da intervenção, testes paramétricos e não paramétricos foram usados, e os resultados foram publicados em outro artigo 11. O número de superfícies expostas e o tempo de exposição (em meses) foram calculados, em cada seguimento, desde o último exame. Além da superfície oclusal, foram incluídas também as superfícies vestibular e lingual. O risco de lesão de cárie é considerado similar quando se comparam a superfície vestibular do molar inferior e as superfícies oclusais do superior e do inferior ${ }^{8}$. Em ordem decrescente de risco, segue a superfície lingual do molar superior e as demais superfícies (lingual do molar inferior e vestibular do molar superior). O produto dessas duas medidas é um valor superfíciemês. A densidade de incidência corresponde ao número de superfícies com lesões de esmalte/ dentina divididas pelo número de superfíciesmês expostas. Os valores de densidade de incidência e respectivos IC95\% foram obtidos. Um modelo ajustado para idade e indicador de risco de cárie foi usado para testar as diferenças nos valores de densidade de incidência de cárie entre os grupos submetidos ao programa modificado e ao convencional depois de 18 meses de seguimento. Dada as características do desfecho, essa análise foi efetuada empregando-se modelo de regressão de Poisson ${ }^{18}$. A razão da densidade de incidência foi estimada adotando-se $\mathrm{p}<0,05$ para rejeição da hipótese de nulidade. O programa Stata 10.0 foi usado (Stata Corp., College Station, Estados Unidos).

Para o cálculo dos custos, foram considerados os gastos diretos relativos aos recursos humanos e materiais. Eles foram calculados com base no valor da quantidade de horas-trabalhador empregada e no valor do consumo de unidades de escova, creme dental e evidenciador de placa bacteriana. A efetividade foi medida pelo número 
de lesões de cárie apurado ao longo do estudo (18 meses). O cálculo do custo-efetividade marginal foi expresso pela diferença de gasto em reais por

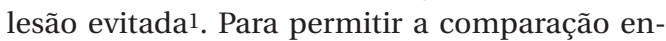
tre os programas, os gastos foram padronizados para o período de 18 meses, e os valores foram ajustados para cada mil crianças, sendo analisados separadamente para meninas e meninos. Os valores, em reais, foram convertidos com base na cotação do dólar comercial para o meio do período do estudo (29/Abr/2008 - US\$ $1=\mathrm{R} \$ 1,70)$.

\section{Resultados}

Valores de kappa para observações repetidas foram excelentes $(>0,93)$, indicando ótima consistência dos exames. Os níveis de flúor nas amostras de água de beber e de creme dental utilizado foram, respectivamente, $0,7 \mathrm{mgF} / \mathrm{L}$ e $1.100 \mu \mathrm{gF} / \mathrm{g}$ para ambos os grupos. Na Figura 1, é mostrado o fluxo dos participantes em cada seguimento. Nas colunas laterais, encontram-se os sujeitos examinados, e, nas colunas centrais, os participantes elegíveis. Na linha de base, 283 sujeitos, nas unidades de controle, e 344, nas unidades de teste, foram examinados. Dos 37 e 53 considerados elegíveis, 36 e 51 foram reexaminados depois de seis meses. Dos 73 e 83 elegíveis no segundo exame, todos foram reexaminados e assim por diante. A perda de sujeitos elegíveis foi de 3,3\% (3/90) e de $2,7 \%$ (8/288), respectivamente, no primeiro e no terceiro seguimento. As lesões de cárie de esmalte/dentina foram analisadas em 284 crianças que atenderam aos critérios de elegibilidade. A distribuição das características da população do estudo nos grupos de comparação foi testada, e nenhuma diferença estatisticamente significativa segundo sexo, cor da pele, idade em meses e ataque de cárie na dentição decídua foi encontrada. Do total, 130 crianças participaram de um seguimento; 68 , de dois; e 86 , de três seguimentos, compreendendo 524 medidas.

Uma diferença de 1,8 lesão por mil superfícies-mês expostas entre os grupos de teste e de controle, durante 18 meses, foi observada, equivalendo a 18 lesões em cada 10 mil superfícies (Tabela 1). Após o ajuste para mil crianças (12 mil superfícies), a diferença foi 21,6 lesões por mil crianças entre os grupos. Disparidade foi notada entre os valores das meninas e dos meninos, respectivamente, 14 e 63 lesões por $10 \mathrm{mil} \mathrm{su-}$ perfícies-mês, implicando diferença de 16,8 e de 75,6 lesões por mil crianças. Valores de densidade de incidência mais favoráveis foram observados no grupo livre de cárie, no exame linha de base. Valores inferiores, conforme o programa, foram observados nos meninos, razão pela qual a ex- periência de cárie na dentição decídua entre os sexos foi comparada. Como os valores de experiência de cárie na dentição decídua para meninas e meninos foram, respectivamente, 1,75 (desvio padrão - DP = 2,65) e 2,69 (DP = 3,79), com um valor de $\mathrm{p}=0,05$ (teste de Mann-Whitney), os resultados da análise múltipla foram apresentados separadamente para cada sexo (Tabela 2). A taxa de incidência foi $10 \%$ maior nas crianças que tinham, pelo menos, um dente decíduo atacado por cárie (meninas RDI = 1,11; IC95\%: 1,01-1,22; $\mathrm{p}=0,026$ e meninos RDI = 1,10; IC95\%: 1,02-1,20; $\mathrm{p}=0,014)$. O programa modificado produziu valores de incidência estatisticamente mais favoráveis nos meninos, independentemente da variação da experiência de cárie e da idade entre eles. A densidade de incidência foi $50 \%$ menor no grupo de teste, comparado ao grupo de controle $(\mathrm{RDI}=0,48$; IC95\%: 0,27-0,87; $\mathrm{p}=0,016$ ).

A ação coletiva envolveu gastos diretos da ordem de R\$ 0,62, por atividade, para as unidades de controle e de $\mathrm{R} \$ 0,61$, por atividade, para as unidades de teste. A frequência das atividades foi maior para as crianças nas unidades de teste (cinco em vez de quatro vezes por ano). O valor da ação, por criança, foi de R $\$ 2,50$ (ou US\$ 1,47) nas unidades de controle e de R $\$ 3,04$ (US\$ 1,79) nas unidades de teste - uma diferença $21,6 \%$ maior para as unidades de teste (Tabela 3). Os gastos com os auxiliares de saúde bucal representaram cerca de $60 \%$ dos gastos totais em ambos os programas.

O custo do programa modificado foi de R\$ 3,04 (US\$ 1,79) anuais por criança, o que representa um acréscimo de $\mathrm{R} \$ 0,54$. O custo marginal ajustado para mil crianças, ao longo de 18 meses, foi de R\$ 810,00. Em relação ao custo da efetividade da ação, pode-se concluir que, para a prevenção de 21,6 lesões, foram gastos $\mathrm{R} \$$ 810,00 (US\$ 476,47).

Na Tabela 4, são apresentados os resultados da avaliação econômica tomando-se, por base, mil crianças. A modificação do programa resultou numa razão de custo-efetividade marginal de $\mathrm{R} \$ 37,50$ (US\$ 22,06) por lesão evitada. Esse valor foi cerca de 3,5 vezes menor entre os meninos (R\$ 10,71 ou US\$ 6,30). Como a efetividade aumentou sem elevar demasiadamente o custo no grupo populacional mais vulnerável, pode-se inferir que foi custo-efetiva nesse grupo.

\section{Discussão}

A avaliação econômica de programas de saúde interessa indivíduos, profissionais de saúde, administradores e formuladores de políticas de saúde 1. Para isso, é necessário definir a intervenção 


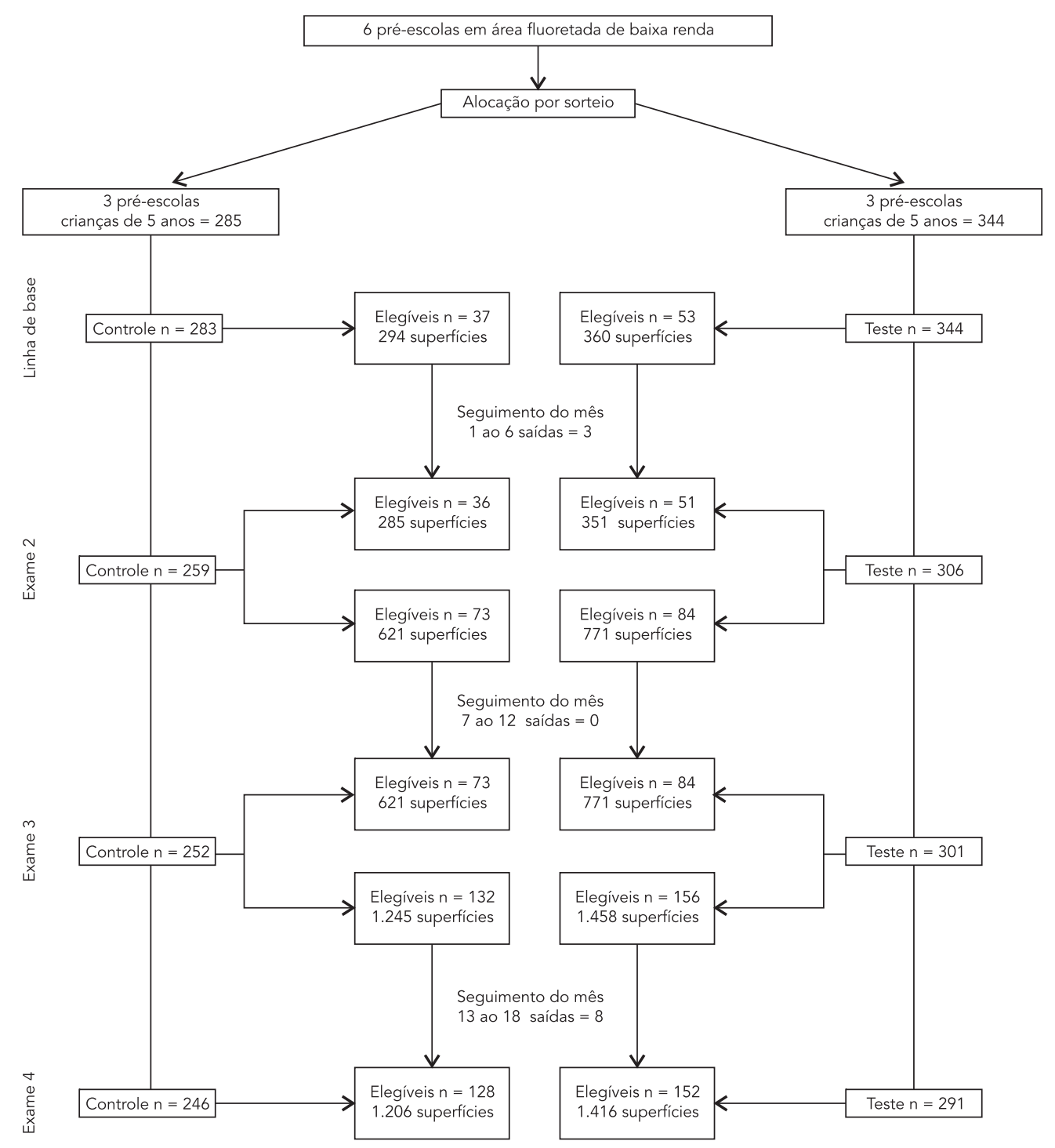

sob o estudo, apresentar a perspectiva da análise, identificar e descrever as alternativas, identificar e medir os custos e as consequências de saúde.

No presente estudo, por razões de ordem ética que contraindicavam a inclusão de um grupo sem acesso ao creme dental fluorado, foi avaliado o custo-efetividade de um programa modificado de escovação dental supervisionada na prevenção da cárie dentária infantil em relação ao programa convencional. Foram examinados os custos diretos na incidência de lesões de cá- rie nos primeiros molares permanentes. Custos indiretos (por exemplo, aqueles ligados ao planejamento, supervisão e avaliação das ações) e outros impactos relacionados à saúde dentária $\mathrm{e}$ à qualidade de vida não foram avaliados.

O programa modificado produziu valores de incidência estatisticamente mais favoráveis nos meninos, independentemente da variação da idade e da experiência de cárie. $\mathrm{O}$ ensaio foi planejado para ser analisado em nível individual. Para isso, era necessário controlar a variação 
Densidade de incidência de lesões de cárie * (por mil superfícies-mês expostas) segundo sexo e experiência de cárie na dentição decídua (ceod), nas unidades de controle e de teste. Estimativas por ponto e por intervalo de confiança. São Vicente, São Paulo, Brasil.

\begin{tabular}{|c|c|c|c|}
\hline & Total & Controle ** & 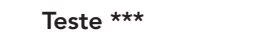 \\
\hline \multicolumn{4}{|l|}{ Sexo } \\
\hline Feminino & $11,3(8,7-13,7)$ & $10,4(6,7-14,1)$ & $11,8(8,4-15,3)$ \\
\hline Masculino & $9,0(6,6-11,4)$ & $12,0(8,3-15,6)$ & $5,7(3,0-8,4)$ \\
\hline \multicolumn{4}{|l|}{ ceod } \\
\hline 0 & $6,1(4,1-8,1)$ & $6,6(4,0-9,3)$ & $5,6(2,8-8,4)$ \\
\hline$>0$ & $14,4(11,6-17,1)$ & $16,1(11,9-20,2)$ & $13,0(9,4-16,5)$ \\
\hline Total & $10,2(8,5-12,0)$ & $11,2(8,6-13,8)$ & $9,4(7,0-11,7)$ \\
\hline
\end{tabular}

Tabela 2

Razão de densidade de incidência (RDI) de lesões de cárie de esmalte/dentina segundo idade, experiência de cárie na dentição decídua (ceod) e o efeito do programa nas meninas e nos meninos. São Vicente, São Paulo, Brasil.

\begin{tabular}{|c|c|c|c|c|c|c|}
\hline \multirow[t]{2}{*}{ Variáveis } & \multicolumn{3}{|c|}{ Meninas } & \multicolumn{3}{|c|}{ Meninos } \\
\hline & RDI & IC95\% & Valor de $p$ * & RDI & IC95\% & Valor de $p$ * \\
\hline Idade (meses) ** & 1,01 & $0,97-1,05$ & 0,649 & 0,97 & $0,93-1,02$ & 0,221 \\
\hline ceod & 1,11 & $1,01-1,23$ & 0,026 & 1,10 & $1,02-1,20$ & 0,014 \\
\hline 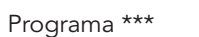 & 1,34 & $0,77-2,34$ & 0,294 & 0,48 & $0,27-0,87$ & 0,016 \\
\hline
\end{tabular}

Estimativas por análise de regressão de Poisson.

* Teste de Wald;

** Início do seguimento;

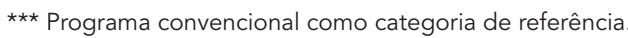

entre as unidades escolares e a variação em nível subindividual. Um número pequeno de unidades foi selecionado, pertencente a uma mesma área de baixa renda e abastecida por água fluoretada. Por essa razão, assumiu-se a exposição relacionada às características das pré-escolas selecionadas semelhante entre os participantes. Além disso, um estimador conectado ao número de superfícies no intervalo de tempo sujeito ao risco foi empregado. Conforme discutido em artigo publicado anteriormente 11, para controlar a precisão das estimativas, uma variável ligada ao risco de cada indivíduo foi acrescentada em modelo multivariado empregado para avaliar taxas de incidência, levando, em consideração, a variação subindividual e entre os sujeitos das unidades de teste e de controle.
Comparando os dois grupos expostos à água e ao creme dental fluorados, verificou-se que um aumento de cerca de $20 \%$ nos custos pode elevar a efetividade da ação, tornando-a melhor custo-efetiva no grupo mais vulnerável. O emprego de creme dental fluorado nos programas de escovação dental supervisionada é o principal argumento junto aos administradores de serviços públicos odontológicos para justificar a necessidade de alocação de recursos para programas preventivos de larga escala. No presente estudo, os meninos que apresentavam história passada do agravo significativamente mais elevada do que as meninas foram os principais beneficiados pela técnica de escovação profissional adotada na intervenção realizada no grupo de teste. Acrescente-se que os grupos comparados 
Indicadores do programa e gastos diretos nas unidades de controle e nas unidades de teste. São Vicente, São Paulo, Brasil.

\begin{tabular}{lcc}
\hline & Tipo de unidade escolar & \\
& Controle & Teste \\
\hline Indicadores do programa & & \\
Média de crianças/ciclo & 744,6 & 661,1 \\
Número de ciclos ou frequência/ano & 4 & 5 \\
Média de períodos */ciclo & 11,8 & 12,0 \\
Total de atividades & $2.978,5$ & $3.305,5$ \\
Gastos diretos (R\$) & & \\
Escova & 625,49 & 631,68 \\
Creme dental & 18,24 & 22,80 \\
Evidenciador de placa & 135,50 & 129,40 \\
Pessoal & $1.080,00$ & $1.226,30$ \\
Total dos gastos & $1,859,25$ & 2010,09 \\
Custo por atividade & 0,62 & 0,61 \\
Custo por criança & 2,50 & 3,04 \\
\hline
\end{tabular}

* Manhã ou tarde.

Custo-efetividade do programa de escovação dental supervisionada modificado. Valores de custo e de incidência ajustados por mil crianças.

\begin{tabular}{|c|c|c|c|c|c|}
\hline Programa & $\begin{array}{l}\text { Custo anual } \\
\text { (R\$) }\end{array}$ & $\begin{array}{c}\text { Efetividade } \\
\text { densidade } \\
\text { incidência *,** }\end{array}$ & $\begin{array}{c}\text { Custo } \\
\text { marginal ** } \\
\text { (R\$) }\end{array}$ & $\begin{array}{l}\text { Efetividade marginal ** } \\
\text { (lesões reduzidas) }\end{array}$ & $\begin{array}{c}\text { Custo- } \\
\text { efetividade } \\
\text { marginal } \star \star \star\end{array}$ \\
\hline Convencional \# & 2.500 & 134,4 & & & \\
\hline Modificado \#\# & 3.040 & 112,8 & 810 & 21,6 & 37,50 \\
\hline Meninas & & & & 16,8 & 48,21 \\
\hline Meninos & & & & 75,6 & 10,71 \\
\hline
\end{tabular}

* Lesões em esmalte/dentina;

** Em 18 meses;

*** Reais por lesão;

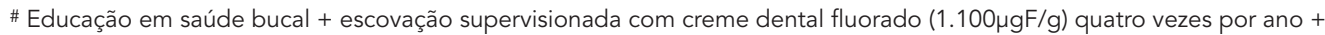
escovação diária com dentifrício fluorado;

\#\# Convencional + escovação profissional com técnica vestíbulo-lingual em molares recém-irrompidos cinco vezes por ano.

não apresentavam diferenças estatisticamente significativas na composição etária, por gênero e em termos de ataque de cárie na dentição decídua ao início do estudo.

Os resultados podem ser atribuídos à frequência mais elevada da escovação profissional e à técnica empregada. Ambos os aspectos podem modificar as condições para acumulação da placa nos molares permanentes 12 . Tais alterações podem facilitar a ação dos fluoretos na superfície oclusal, uma área menos susceptível ao tratamento com flúor. Revisão sistemática mostrou que o efeito do creme dental fluorado aumenta conforme a frequência de uso e a presença de supervisão 5 . O programa modificado foi realizado cinco vezes por ano, enquanto o convencional, quatro vezes por ano. Sem considerar o primeiro e o último mês do ano, o programa modificado foi aplicado a cada 45 dias, enquanto o convencional, a cada 60 dias. Se fossem considerados 
os 12 meses, o intervalo médio seria 60 e 75 dias respectivamente, mas, na prática, o programa tem início a partir do segundo mês do ano e se encerra antes do último mês.

Decisões a respeito de custo-efetividade de tecnologias em saúde dificilmente eliminam ou neutralizam todas as fontes potenciais de incerteza. No presente estudo, as principais fontes de incerteza estão associadas ao modelo determinístico usado na análise dos dados. Tanto o volume de recursos como as consequências da intervenção foram apropriadamente controlados. A incidência de cárie foi subestimada em ambos os grupos. Lesões de cárie não cavitadas iniciais ou avançadas ou aquelas cuja cavitação atingia até $0,5 \mathrm{~mm}$ não foram consideradas como superfícies cariadas, evitando dificuldades relacionadas ao fenômeno de reversão das lesões. Além disso, apenas um examinador de elevada consistência, sem conhecimento sobre as características das intervenções nas pré-escolas, foi empregado.

Poderia ser considerado que as diferenças de risco entre meninos e meninas associadas ao ataque de cárie na dentição decídua observadas no início da intervenção expressariam aspectos relativos às diferenças de cuidado oferecido pelos pais aos filhos e às filhas não controlados no estudo. Entretanto, se isso tivesse influenciado os resultados, as meninas seriam as maiores beneficiadas pelo programa modificado.

Foram gastos R\$ 35,50 (ou US\$22,06) por lesão evitada na comparação entre o programa modificado e o convencional. Entre os meninos, o valor foi 3,5 vezes menor. Na Catalunha (Espanha), o custo-efetividade de um programa de escovação supervisionada comparado a nenhuma intervenção foi estimado em US\$11.09 por lesão evitada 10. Na Finlândia, a oferta de um programa individualizado de controle de cárie em escolares de 11-12 anos comparado a um programa convencional representou um custo-efetividade marginal de $€ 34,07$ por lesão evitada 19 . No grupo mais vulnerável representado pelos meninos, esse valor foi US\$ 6.30 dólares no presente estudo.

Diante desses resultados, parece lícito concluir que a efetividade da escovação dental supervisionada com creme dental fluorado, uma política pública largamente aplicada no Brasil, pode ser aumentada se os auxiliares odontológicos forem treinados para aplicar a técnica de escovação vestíbulo-lingual. Tais auxiliares estão em operação nos serviços públicos odontológicos, mas não se tem conhecimento de protocolos que orientem a ação desse pessoal para uma atuação mais efetiva nas crianças em fase de irrompimento dos primeiros molares permanentes. Essa fase é de particular interesse para a condi- ção dentária, dado que favorece o acúmulo de placa bacteriana e o ataque de cárie na superfície oclusal 12 .

Essa medida, se aplicada em larga escala num prazo duas vezes maior, pode elevar o custo-efetividade da ação e produzir uma redução substantiva das necessidades de tratamento odontológico da população em idade escolar, criando condições para que parte dos recursos odontológicos disponíveis seja redirecionada para grupos tradicionalmente excluídos dos programas de atenção à saúde bucal.

Por fim, cabem alguns comentários sobre o modelo de intervenção adotado. No presente estudo, foi aplicado um modelo no qual o caráter programático das ações e a epidemiologia ocupam papel central e criam condições para o uso racional dos recursos existentes, visando a melhor relação de custo-efetividade e a aplicação do princípio da equidade, isto é, oferecer mais ações a quem mais necessita delas, com base em critério de risco. Nesse aspecto, programas de saúde bucal coletiva, bem estruturados, em pré-escolas e escolas de 1 o grau podem adotar, pelos menos, duas estratégias: uma direcionada aos subgrupos populacionais de maior risco e outra focalizada nos indivíduos de alto risco.

A primeira, conhecida pela expressão targeted-population approach 20 , faz uso de fontes de dados secundários para identificar essas comunidades, prescindindo, portanto, de exames individuais periódicos. A segunda, por ser uma abordagem focada em indivíduos, faz uso de técnicas de rastreamento em levantamentos epidemiológicos anuais e outras informações ligadas ao indivíduo com a finalidade de identificar aqueles (cerca de $20-30 \%$ ) que, segundo o sexo e a idade, apresentam maior atividade de cárie dentária que os demais. O debate acerca dessas alternativas é contemporâneo e mostra a relevância de estudos que aportem conhecimentos para subsidiar os tomadores de decisão em saúde bucal coletiva.

O modelo de intervenção investigado se apoiou na primeira abordagem. Não se fez uso de indicadores para identificar, previa e individualmente, as crianças de risco. Somente após a intervenção, na etapa de análise dos dados, foi constatado que, na população do estudo, dentição decídua com, pelo menos, um dente atacado por cárie e meninos comparados às meninas eram indicadores de risco. Em futuros estudos, outros indicadores poderiam ser apreciados. No que pesem as limitações da abordagem individualizada de risco 21 , sob certas condições, determinadas hipóteses poderiam ser testadas, combinando ambas as abordagens. Os auxiliares odontológicos poderiam ser treinados para 
identificar crianças de risco elevado à cárie, em fase de irrompimento dos primeiros molares permanentes, empregando indicadores simples de fácil detecção. A resposta para a questão se tal providência é capaz de aumentar sensivelmente o custo-efetividade da escovação dental supervisionada somente poderá ser obtida com novos estudos.

\section{Conclusão}

O programa modificado custou cerca de $\mathrm{R} \$ 3,04$ por criança, resultando numa razão de custo-efetividade marginal de R $\$ 35,50$ por lesão evitada, sendo cerca de R $\$ 10,00$ por lesão evitada entre os meninos (grupo de maior risco). Considerando a curta duração do seguimento, a exposição de ambos os grupos à água e ao creme dental fluorados e os resultados significativos obtidos entre os meninos, é lícito projetar um efeito relevante num período duas vezes maior (36 meses), num subgrupo populacional com experiência anterior de cárie reconhecida como de maior risco. Os resultados obtidos encorajam fortemente o prosseguimento de estudos nessa direção, sugerindo uma redução significativa de cárie numa maior escala populacional que poderá representar substancial diminuição nas necessidades de tratamento odontológico.

\section{Resumo}

O custo-efetividade de um programa modificado de escovação dental supervisionada foi comparado ao programa convencional. Participaram 284 crianças de 5 anos com, pelo menos, um molar permanente com a superfície oclusal irrompida/hígida. Nas unidades de controle, o programa convencional composto de atividade educativa com distribuição de escova e creme dental fluorado foi desenvolvido quatro vezes por ano. Nas unidades de teste, as crianças receberam também escovação profissional nas superfícies oclusais desses dentes, realizada por auxiliar de saúde bucal, empregando-se a técnica de escovação vestíbulo-lingual cinco vezes por ano. Cárie de esmalteldentina foi registrada nas superfícies vestibular, oclusal e lingual dos molares permanentes durante 18 meses. A razão da densidade de incidência (RDI) foi estimada usando o modelo de regressão de Poisson, sendo 50\% menor entre os meninos no grupo de teste $(p=0,016)$. O programa modificado custou $R \$ 3,04$ por criança. A razão de custo-efetividade marginal foi de $R \$ 10,71$ por lesão evitada entre os meninos. O programa modificado foi custo-efetivo nos meninos.

Cárie Dentária; Escovação Dentária; Dente Molar; Prevenção Primária; Avaliação de Programas e Projetos de Saúde

\section{Agradecimentos}

Minha gratidão às cirurgiães-dentistas Maria Helena Miguel Gonzalez, Marcela Alessandra Bozzella e Cecília de Ávila Rando Ruas e às auxiliares Janete Giponi Costa Tenório e Alcimara das Dores do Nascimento, profissionais da Secretaria Municipal de Saúde de São Vicente. Agradeço também ao Prof. Jaime Cury, da Faculdade de Odontologia da Universidade Estadual de Campinas, responsável pelo controle dos teores de flúor em amostras de água e de creme dental. Projeto subvencionado pelo auxílio à pesquisa da Fundação de Amparo à Pesquisa do Estado de São Paulo (FAPESP; processo no. 06/51300-00). 


\section{Referências}

1. Drummond MF, O’Brien B, Stoddart GL, Torrance GW. Methods for the economic evaluation of health care programmes. 2nd Ed. New York: Oxford University Press; 2001.

2. Frazão P. Tecnologias em saúde bucal coletiva. In: Botazzo C, Freitas SFT, organizadores. Ciências sociais e saúde bucal: questões e perspectivas. Bauru: Editora Unesp; 1998. p. 159-174.

3. Carvalho LAC, Scabar LF, Souza DS, Narvai PC. Procedimentos coletivos de saúde bucal: gênese, apogeu e ocaso. Saúde Soc 2009; 18:490-9.

4. Chaves SCL, Vieira-da-Silva LM. A efetividade do dentifrício fluoretado no controle da cárie dental: uma meta-análise. Rev Saúde Pública 2002; 36:598-606

5. Marinho VCC, Higgins JPT, Logan S, Sheiham A. Fluoride toothpastes for preventing dental caries in children and adolescents. Cochrane Database Syst Rev 2003; (1):CD002278.

6. Narvai PC, Frazão P, Roncalli AG, Antunes JL. Cárie dentária no Brasil: declínio, polarização, iniquidade e exclusão social. Pan Am J Pub Health 2006; 19:385-393.

7. Frazão P, Castellanos RA. La participación del personal auxiliar de odontología en los sistemas locales de salúd. Rev Panam Salud Pública 1999; 5: 106-15.

8. Batchelor PA, Sheiham A. Grouping of tooth surfaces by susceptibility to caries: a study in 5-16 year-old children. BMC Oral Health 2004; 4:2.

9. Künzel VW, Blüthner K. Economic aspects of organized and supervised oral hygiene drives. Stomatol DDR 1976; 26:654-7.

10. Manau C, Cuenca E, Martínez-Carretero J, Salleras L. Economic evaluation of community programs for the prevention of dental caries in Catalonia, Spain. Community Dent Oral Epidemiol 1987; 15:297-300.

11. Frazão P. Effectiveness of the bucco-lingual technique within a school-based supervised toothbrushing program on preventing caries: a randomized controlled trial. BMC Oral Health 2011; 11:11.
12. Carvalho JC, Thylstrup A, Ekstrand KR. Results after 3 years of non-operative occlusal caries treatment of erupting permanent first molars. Community Dent Oral Epidemiol 1992; 20:187-92

13. Nourallah AW, Splieth CH. Efficacy of occlusal plaque removal in erupting molars: a comparison of an electric toothbrush and the cross-toothbrushing technique. Caries Res 2004; 38:91-4.

14. Gonçalves AF, de Oliveira Rocha R, Oliveira MD et al. Clinical effectiveness of toothbrushes and toothbrushing methods of plaque removal on partially erupted occlusal surfaces. Oral Health Prev Dent 2007; 5:33-7

15. World Health Organization. Oral health surveys: basic methods. 4th Ed. Geneva: World Health Organization; 1997.

16. Pitts NB, Fyffe HE. The effect of varying diagnostic thresholds upon clinical caries data for a low prevalence group. J Dent Res 1988; 67:592-6.

17. Meinert CL. Clinical trials: design, conduct and analysis. New York: Oxford University Press; 1986.

18. Hujoel PP, Isokangas PJ, Tiekso J, Davis S, Lamont RJ, DeRouen TA, et al. A re-analysis of caries rates in a preventive trial using poisson regression models. J Dent Res 1994; 73:573-9.

19. Hietasalo P, Seppä L, Lahti S, Niinimaa A, Kallio J, Aronen P, et al. Cost-effectiveness of an experimental caries-control regimen in a 3.4-yr randomized clinical trial among 11-12-yr-old Finnish schoolchildren. Eur J Oral Sci 2009; 117:728-33.

20. Burt BA. Concepts of risk in dental public health. Community Dent Oral Epidemiol 2005; 33:240-7.

21. Batchelor PA, Sheiham A. The distribution of burden of dental caries in schoolchildren: a critique of the high-risk caries prevention strategy for populations. BMC Oral Health 2006; 6:3.

Recebido em 15/Fev/2011

Versão final reapresentada em 06/Jul/2011 Aprovado em 26/Set/2011 